\title{
Editorial Manager(tm) for AIDS
}

Manuscript Draft

Manuscript Number:

Title: Preserved Monocyte-Derived Dendritic Cell Differentiation and Maturation in the Presence of HIV-2 Envelope

Article Type: Concise Communication

Section/Category:

Keywords: HIV-2; HIV envelope proteins; gp105; HIV immunopathogenesis; Dendritic cells.

Corresponding Author: Dr. Ana E Sousa, M.D., PhD

Corresponding Author's Institution: Instituto de Medicina Molecular, Faculdade de Medicina, Universidade de Lisboa

First Author: Rita Cavaleiro, BSc, MSc

Order of Authors: Rita Cavaleiro, BSc, MSc; António P Baptista, DVM; Russell B Foxall, BSc, MSc; Rui M Victorino, M.D., PhD; Ana E Sousa, M.D., PhD

Manuscript Region of Origin:

Suggested Reviewers: Richard A Koup

Immunology Laboratory, Vaccine Research Center, NIAID

rkoup@mail.nih.gov

Sandra Gessani

Department of Cell Biology and Neurosciences, Istituto Superiore di Sanità gessani@iss.it 
Teunis B Geijtenbeek

Department of Molecular Cellular Biology and Immunology, VU University Medical Center

T.Geijtenbeek@vumc.nl

Opposed Reviewers: 


\title{
Title: Preserved Monocyte-Derived Dendritic Cell Differentiation and Maturation in the Presence of HIV-2 Envelope
}

\begin{abstract}
Background: Dendritic cells (DC) are fundamental for the initiation of immune responses and are important players in AIDS immunopathogenesis. Impairment of DC function may result from bystander effects of HIV-1 envelope proteins independently of direct HIV-1 infection. HIV-2 envelope proteins are thought to interact with a broader range of receptors than those of HIV-1, and have been shown to have T-cell immunossuppressive properties mediated by monocytes.
\end{abstract}

Objective: Investigate the effects of HIV-2 envelope on DC differentiation and maturation.

Methods: The modulatory properties of HIV- $2_{\mathrm{ROD}}$ envelope on DC generated from monocytes were assessed using both recombinant protein and whole chemically (aldrithiol-2 treated) inactivated virus. DC phenotype was assessed by flow cytometry and DC function by their ability to stimulate allogeneic T-cells and to produce cytokines.

Results and Conclusion: We demonstrate that HIV-2 Env had no effects upon DC differentiation and maturation despite its broad receptor usage and ability to modulate monocyte function. Our data support the possibility that preservation of DC function may contribute to the relatively benign course of HIV-2 disease. Understanding the mechanisms that prevent HIV-2 from impairing DC function may provide new therapeutic targets. 


\section{Concise Communication}

Title: Preserved Monocyte-Derived Dendritic Cell Differentiation and Maturation in the Presence of HIV-2 Envelope

\section{Running Head: HIV-2 Env Effects on Dendritic Cells}

Rita Cavaleiro ${ }^{1}$, António P. Baptista ${ }^{1}$, Russell B. Foxall ${ }^{1}$, Rui M. M. Victorino ${ }^{1,2}$, Ana E. Sousa $^{1 *}$.

${ }^{1}$ Unidade de Imunologia Clínica, Instituto de Medicina Molecular, Faculdade de Medicina, Universidade de Lisboa, Av. Prof. Egas Moniz, 1649-028 Lisboa, Portugal

${ }^{2}$ Clínica Universitária de Medicina 2, Hospital de Santa Maria, Av. Prof. Egas Moniz, 1649-028 Lisboa, Portugal

Text Word Count: 1587

This work was supported by grants from "Fundação para a Ciência e a Tecnologia" (FCT) and by "Programa Operacional Ciência e Inovação 2010" (POCI2010) to AES. RC and RBF received scholarships from FCT co-financed by POCI 2010 and FSE, and AB from GlaxoSmithKline.

*Corresponding Author:

Ana E. Sousa, MD PhD

Unidade de Imunologia Clínica, Instituto de Medicina Molecular, Faculdade de Medicina de Lisboa, Av. Prof. Egas Moniz, 1649-028 Lisboa, Portugal.

Phone: 351217999521 Fax: 351217999527

E-mail: asousa@fm.ul.pt 


\begin{abstract}
Background: Dendritic cells (DC) are fundamental for the initiation of immune responses and are important players in AIDS immunopathogenesis. Impairment of DC function may result from bystander effects of HIV-1 envelope proteins independently of direct HIV-1 infection. HIV-2 envelope proteins are thought to interact with a broader range of receptors than those of HIV-1, and have been shown to have T-cell immunossuppressive properties mediated by monocytes.
\end{abstract}

Objective: Investigate the effects of HIV-2 envelope on DC differentiation and maturation.

Methods: The modulatory properties of HIV-2 $2_{\mathrm{ROD}}$ envelope on DC generated from monocytes were assessed using both recombinant protein and whole chemically (aldrithiol2 treated) inactivated virus. DC phenotype was assessed by flow cytometry and DC function by their ability to stimulate allogeneic T-cells and to produce cytokines.

Results and Conclusion: We demonstrate that HIV-2 Env had no effects upon DC differentiation and maturation despite its broad receptor usage and ability to modulate monocyte function. Our data support the possibility that preservation of DC function may contribute to the relatively benign course of HIV-2 disease. Understanding the mechanisms that prevent HIV-2 from impairing DC function may provide new therapeutic targets.

\title{
Key words:
}

HIV-2; HIV envelope proteins; gp105; HIV immunopathogenesis; Dendritic cells. 


\section{Introduction}

Dendritic cell (DC) disturbances are thought to significantly contribute to AIDS pathogenesis (recently reviewed in $[1,2]$ ). In addition to direct human immunodeficiency virus (HIV) type 1 infection of these professional antigen-presenting cells, viral envelope (Env) proteins per se are able to induce a significant impairment of DC function [2-7]. The HIV-1 surface glycoprotein, gp 120, is readily shed from the cell surface due to its noncovalent association with the transmembrane Env gp41, exerting modulatory effects on bystander cells through binding to CD4, chemokine receptors or other molecules expressed by DC, such as lectins [8-10]. HIV-1 Env proteins were shown to functionally impair isolated primary $\mathrm{DC}[2,3,11]$, as well as the in vitro development and maturation of monocyte-derived DC [4-7]. HIV-2, which is associated with an attenuated form of HIV/AIDS disease as compared to HIV-1 [12-19], has a broader range of coreceptor usage [20-22] and elicits higher levels of neutralizing antibodies [23], suggesting that its Env has structurally distinct properties. Moreover, the external component of HIV2 $2_{\text {ROD }}$ Env, gp105, unlike gp120 of HIV-1, was shown to bind to the CD8 molecule with high affinity [24] and to induce higher levels of beta-chemokines [25]. We have also shown that HIV2 $2_{\text {ROD }}$ gp105 induced marked suppression of in vitro lymphoproliferation to both recall antigens and antiCD3 through a monocyte contact-dependent mechanism as well as high levels of TNF- $\alpha$ production $[26,27]$. Thus, it is reasonable to hypothesize that HIV2 $2_{\text {ROD }}$ gp105 significantly impacts on DC differentiation and maturation in vitro. 


\section{Methods}

Recombinant Env protein (gp105 from HIV-2 ${ }_{\text {ROD }}$ produced in a baculovirus expression system; EU Programme EVA, MRC, UK) as well as whole chemically inactivated virus were used. HIV-2 $2_{\text {ROD }}$ grown on $\mathrm{H} 9$ cells was inactivated at $4{ }^{\circ} \mathrm{C}$ with $1 \mathrm{mM}$ aldrithiol-2 (AT-2; Sigma-Aldrich, St Louis, MO) and purified and concentrated using a protocol kindly provided by J. Lifson and J. Bess [28]. Inactivation was shown to disrupt the nucleocapsid without changing the conformational and functional integrity of the surface Env glycoproteins [29]. Given that only about $0,1 \%$ of circulating virions are infectious, it is believed that the exposure of host cells to inactivated HIV may more accurately mimic the most frequent type of in vivo cell-virion interaction [2].

A standard in vitro DC differentiation system was used. Briefly, monocytes were magnetically isolated from peripheral blood mononuclear cells (PBMC) of healthy donors' buffy coats (Portuguese Institute of Blood) with CD14 Microbeads (Miltenyi Biotec, Bergish Gladbach, Germany). Immature DC (iDC) were generated by culturing monocytes $\left(3 \times 10^{6}\right)$ for 6 days in RPMI 1640 medium (Gibco-Invitrogen, Paisley, UK) containing 10\% fetal calf serum (Sigma-Aldrich), penicillin/streptomycin (100U/100mg/ml; GibcoInvitrogen), glutamine (2mM; Gibco-Invitrogen) plus GM-CSF (50 ng/ml; R\&D Systems, Minneapolis, MN) and IL-4 (20 ng/ml; R\&D Systems), in the absence or presence of recombinant gp 105 $\mathrm{ROD}(1 \mu \mathrm{g} / \mathrm{ml})$ or the whole inactivated HIV-2 ${ }_{\mathrm{ROD}}(\mathrm{HIV}-2 \mathrm{Tx} ; 300 \mathrm{ng}$ of p26 Ag equivalent $/ \mathrm{ml}$ ) at $37^{\circ} \mathrm{C}$ in a humidified atmosphere of $5 \% \mathrm{CO}_{2}$.

DC phenotype was assessed by flow cytometry using a panel of monoclonal antibodies against HLA-DR, CD80, CD86 and CD83 (all from BD Biosciences, San Jose, CA), as well as PD-L1 and PD-L2 (from eBioscience, San Diego, CA), as previously described 
[26]. Samples were acquired using a FACSCalibur flow cytometer (BD Biosciences) and analysed using CellQuest (BD Biosciences) and FlowJo (Tree Star, Ashland, OR).

In order to assess if the presence of gp $105_{\mathrm{ROD}}$ during $\mathrm{DC}$ differentiation from monocytes impaired the subsequent DC maturation, DC were stimulated with lipopolysaccharide (LPS; 100 ng/ml; Sigma-Aldrich) for 48 hours.

DC function was further assessed by measuring cytokine production in culture supernatants by ELISA from eBiosciences as well as by evaluating their allostimulatory capability in a mixed-leukocyte reaction. DC were co-cultured with purified allogeneic $\mathrm{T}$ cells $\left(1 \times 10^{5}\right.$ cells; Pan T cell Isolation Kit; Miltenyi Biotec) at different DC: T cell ratio. Proliferation was measured after a 5-day culture by $\left[{ }^{3} \mathrm{H}\right]$ thymidine incorporation (Amersham Pharmacia Biotech, Little Chalfont, UK) after a pulse of $1 \mu \mathrm{Ci}$ during the final $18 \mathrm{~h}$ culture, and cpm were counted in a gaseous scintillation $\beta$-counter (Packard, Meriden, CT, USA). Results were analyzed as stimulation indexes calculated by dividing the cpm obtained in DC: T cell co-culture by the cpm obtained in T cells cultured alone.

\section{Results}

As shown in Fig. 1A, iDC derived from monocytes in the presence of gp $105_{\mathrm{ROD}}$ (iDC/gp105) exhibited expression levels of HLA-DR, CD80, CD86 and CD83 similar to those generated in its absence. The iDC generated in the presence of gp $105_{\text {ROD }}$ were fully competent to undergo subsequent LPS-induced maturation as evaluated phenotypically by

flow cytometry (Fig. 1A) and morphologically by optical microscopy (data not shown). As shown in Fig. 1B, DC differentiated in the presence or absence of gp105 showed similar allostimulatory activity after subsequent LPS-induced maturation. 
In parallel, similar experiments were performed using whole inactivated virus. As illustrated in Fig. 1E, the treatment with AT-2 fully abrogated viral replication in activated PBMC as documented by the absence of p24 in the supernatants as assessed by ELISA. Microvesicles, prepared from supernatants of uninfected H9 cells using the same procedures used to prepare HIV-2Tx, were used as negative control in all the HIV-2Tx experiments and found to induce no effects (data not shown). Similarly to gp105, the presence of HIV-2Tx during DC differentiation from monocytes did not alter DC phenotype (Fig. 1C), nor did it affect their ability to mature upon LPS stimulation as assessed by the DC morphology (data not shown), expression of co-stimulatory molecules (Fig. 1C) or ability to stimulate allogeneic T cells (Fig. 1D). Programmed death-1 (PD-1) signalling mediates an inhibitory pathway of T-cell responses and its over-expression is currently considered to contribute significantly to the impairment of specific T-cell responses in HIV-1 infected individuals [30]. HIV-1 disease progression is also associated with an up-regulation of PD-L1, a PD-1 ligand [31], and, moreover, HIV-1 derived TLR7/8 ligands were shown to induce PD-L1 expression on DC and monocytes [32]. Therefore, we also assessed whether the expression of PD-1 ligands, PD-L1 and PD-L2, were upregulated upon HIV-2Tx exposure. No significant alterations were induced by the presence of the whole inactivated virus (Fig. 1C).

In summary, our data showed that the HIV-2 Env tested does not affect monocyte differentiation into DC.

Next we asked whether HIV-2 $2_{\text {ROD }}$ Env per se was able to induce DC maturation and if the presence of HIV-2 $2_{\text {ROD }}$ Env concomitantly with LPS might modulate this process. For this purpose, iDC were cultured for $48 \mathrm{~h}$ in the absence or presence of either gp $105_{\mathrm{ROD}}$ (Fig. 2A and 2B) or HIV-2Tx (Fig. 2C e 2D) with or without LPS, and evaluated with respect to 
their morphology (data not shown), phenotype and allostimulatory capacity. As illustrated in Fig. 2, iDC exposed to gp105 ROD or HIV-2Tx did not exhibit differences in the expression of maturation markers as compared to unexposed iDC. On the other hand, DC maturation induced by LPS was not affected by the presence of either gp $105_{\mathrm{ROD}}$ or HIV2Tx during this process (Fig. 2). Thus, we conclude that the HIV-2 Env tested was unable to induce DC maturation per se, and, moreover, did not affect LPS-induced DC maturation. Of note, similar findings were obtained using higher concentrations of protein or virus (supplemental figure).

We have previously reported that HIV-2 gp105 ROD induces high levels of TNF- $\alpha$ production by monocytes [26]. Therefore, we investigated whether DC exposure to either gp105 ${ }_{\text {ROD }}$ or HIV-2Tx could modify their ability to secrete TNF- $\alpha$ or IL-10, an immunosuppressive cytokine shown to be induced by HIV-1 Env [2]. Cytokines were measured by ELISA in supernatants post-48h culture. As shown in Fig. 2E, secretion of both cytokines in the absence or the presence of LPS was not significantly altered by the presence of either gp105 $\mathrm{ROD}$ or HIV-2Tx, as compared to unexposed DC.

\section{Discussion}

To our knowledge, there are no previous studies on the effects of HIV-2 Env on DC differentiation and maturation. We report here no significant alterations induced by the presence of Env recombinant protein or whole chemically inactivated HIV-2 ${ }_{\text {ROD }}$ on DC differentiation from monocytes or in their maturation upon LPS stimulation, as assessed by morphology, expression of co-stimulatory molecules, cytokine production and allostimulatory ability. 
Remarkably, the same recombinant protein was previously shown to significantly alter monocyte and T-cell function [26, 27]. Despite some discrepant results according to the strains used, it is widely accepted that HIV-1 Env triggers signalling events that result in abnormal monocyte-derived DC differentiation and maturation in vitro and induces significant disturbances of primary DC function [2]. Circulating DC from HIV-1 infected patients exhibit quantitative and qualitative abnormalities [33-36] and Env has been implicated in these impairments $[2,3,11]$. In agreement with a distinct impact of HIV-2 and HIV-1 on DC, it was recently shown that primary DC are less susceptible to HIV-2 than HIV-1 infection in vitro using both HIV-2 CCR5 primary isolates and a CXCR4 labadapted virus [37]. More HIV-2 strains should be studied to complement our data based on a lab-adapted CXCR4 using strain. Nevertheless, our results suggest that HIV-2 Env may not significantly affect monocyte-derived DC and raise the possibility that myeloid DC may be spared in HIV-2 infection.

HIV-2 is associated with slow rate of AIDS progression and low viremia [15-19, 22, 3739]. DC play a central role in the generation of immune responses against HIV and opportunistic infections. Moreover, DC may be important in the modulation of HIVassociated immunopathology $[1,2]$. Our data raise the possibility that a preservation of DC function may contribute to the relatively benign HIV-2 immunodeficiency. Identification of possible factors that prevent HIV-2 from impairing DC function may significantly increase our understanding of AIDS pathogenesis and provide new therapeutic targets.

\section{Acknowledgements}

We would like to thank J. Lifson and J. Bess (NIH, Bethesda) for technical advice in the preparation of the inactivated HIV-2, João Gonçalves from Faculty of Pharmacy of Lisbon 
for sharing reagents, the Portuguese Institute of Blood for providing the buffy coats, as well as the NIBSC Centralized facility for AIDS Reagents supported by EU Programme EVA (contract QLK2-CT-1999-00609) and the UK Medical Research Council for providing recombinant HIV-2 gp105 ROD. Authors' Contribution: RC designed and performed research, analysed and discussed the data and wrote the paper; APB and RBF contributed to research and discussed results; RMMV critically discussed the data and manuscript; AES designed research, analysed and discussed the data and wrote the paper. This work was supported by grants from "Fundação para a Ciência e a Tecnologia" (FCT) and by "Programa Operacional Ciência e Inovação 2010" (POCI2010) to AES. RC and RBF received scholarships from FCT co-financed by POCI 2010 and FSE, and AB from GlaxoSmithKline.

\section{References}

1. Piguet V, Steinman RM. The interaction of HIV with dendritic cells: outcomes and pathways. Trends Immunol 2007; 28: 503-510.

2. Chougnet $\mathrm{C}$, Gessani $\mathrm{S}$. Role of gp120 in dendritic cell dysfunction in HIV infection. J Leukoc Biol 2006; 80: 994-1000.

3. Martinelli E, Cicala C, Van Ryk D, Goode DJ, Macleod K, Arthos J, et al. HIV-1 gp120 inhibits TLR9-mediated activation and IFN-\{alpha\} secretion in plasmacytoid dendritic cells. Proc Natl Acad Sci U S A 2007; 104: 3396-3401.

4. Fantuzzi L, Purificato C, Donato K, Belardelli F, Gessani S. Human immunodeficiency virus type 1 gp120 induces abnormal maturation and 
functional alterations of dendritic cells: a novel mechanism for AIDS pathogenesis. $J$ Virol 2004; 78: 9763-9772.

5. Williams MA, Trout R, Spector SA. HIV-1 gp120 modulates the immunological function and expression of accessory and co-stimulatory molecules of monocyte-derived dendritic cells. J Hematother Stem Cell Res 2002; 11: 829-847.

6. Harman AN, Wilkinson J, Bye CR, Bosnjak L, Stern JL, Nicholle M, et al. HIV induces maturation of monocyte-derived dendritic cells and Langerhans cells. $J$ Immunol 2006; 177: 7103-7113.

7. Zhang R, Lifson JD, Chougnet C. Failure of HIV-exposed CD4+ T cells to activate dendritic cells is reversed by restoration of CD40/CD154 interactions. Blood 2006; 107: 1989-1995.

8. Chirmule N, Pahwa S. Envelope glycoproteins of human immunodeficiency virus type 1: profound influences on immune functions. Microbiol Rev 1996; 60: 386-406.

9. He B, Qiao X, Klasse PJ, Chiu A, Chadburn A, Knowles DM, et al. HIV-1 envelope triggers polyclonal Ig class switch recombination through a CD40independent mechanism involving BAFF and C-type lectin receptors. $J$ Immunol 2006; 176: 3931-3941.

10. Lee C, Liu QH, Tomkowicz B, Yi Y, Freedman BD, Collman RG. Macrophage activation through CCR5- and CXCR4-mediated gp120-elicited signaling pathways. J Leukoc Biol 2003; 74: 676-682.

11. Fonteneau JF, Larsson M, Beignon AS, McKenna K, Dasilva I, Amara A, et al. Human immunodeficiency virus type 1 activates plasmacytoid dendritic cells 
and concomitantly induces the bystander maturation of myeloid dendritic cells. J Virol 2004; 78: 5223-5232.

12. Poulsen AG, Aaby P, Larsen O, Jensen H, Naucler A, Lisse IM, et al. 9-year HIV2-associated mortality in an urban community in Bissau, west Africa. Lancet 1997; 349: 911-914.

13. Marlink R, Kanki P, Thior I, Travers K, Eisen G, Siby T, et al. Reduced rate of disease development after HIV-2 infection as compared to HIV-1. Science 1994; 265: $1587-1590$.

14. Jaffar S, Wilkins A, Ngom PT, Sabally S, Corrah T, Bangali JE, et al. Rate of decline of percentage CD4+ cells is faster in HIV-1 than in HIV-2 infection. $J$ Acquir Immune Defic Syndr Hum Retrovirol 1997; 16: 327-332.

15. Sousa AE, Carneiro J, Meier-Schellersheim M, Grossman Z, Victorino RM. CD4 T cell depletion is linked directly to immune activation in the pathogenesis of HIV-1 and HIV-2 but only indirectly to the viral load. J Immunol 2002; 169: 3400-3406.

16. Grossman Z, Meier-Schellersheim M, Sousa AE, Victorino RM, Paul WE. CD4+ T-cell depletion in HIV infection: are we closer to understanding the cause? Nat Med 2002; 8: 319-323.

17. Albuquerque AS, Cortesao CS, Foxall RB, Soares RS, Victorino RM, Sousa AE. Rate of increase in circulating IL-7 and loss of IL-7Ralpha expression differ in HIV-1 and HIV-2 infections: two lymphopenic diseases with similar hyperimmune activation but distinct outcomes. J Immunol 2007; 178: 32523259. 
18. Rowland-Jones SL, Whittle HC. Out of Africa: what can we learn from HIV-2 about protective immunity to HIV-1? Nat Immunol 2007; 8: 329-331.

19. Drylewicz J, Matheron S, Lazaro E, Damond F, Bonnet F, Simon F, et al. Comparison of viro-immunological marker changes between HIV-1 and HIV2-infected patients in France. AIDS 2008; 22: 457-468.

20. Azevedo-Pereira JM, Santos-Costa Q, Moniz-Pereira J. HIV-2 infection and chemokine receptors usage - clues to reduced virulence of HIV-2. Curr HIV Res $2005 ; 3: 3-16$.

21. McKnight A, Dittmar MT, Moniz-Periera J, Ariyoshi K, Reeves JD, Hibbitts S, et al. A broad range of chemokine receptors are used by primary isolates of human immunodeficiency virus type 2 as coreceptors with CD4. J Virol 1998; 72: $4065-4071$.

22. Soares R, Foxall R, Albuquerque A, Cortesao C, Garcia M, Victorino RM, et al. Increased frequency of circulating CCR5+ CD4+ $T$ cells in human immunodeficiency virus type 2 infection. $J$ Virol 2006; 80: 12425-12429.

23. Bjorling E, Scarlatti G, von Gegerfelt A, Albert J, Biberfeld G, Chiodi F, et al. Autologous neutralizing antibodies prevail in HIV-2 but not in HIV-1 infection. Virology 1993; 193: 528-530.

24. Kaneko H, Neoh LP, Takeda N, Akimoto H, Hishikawa T, Hashimoto H, et al. Human immunodeficiency virus type 2 envelope glycoprotein binds to CD8 as well as to CD4 molecules on human T cells. J Virol 1997; 71: 8918-8922.

25. Neoh LP, Akimoto H, Kaneko H, Hishikawa T, Hashimoto H, Hirose S, et al. The production of beta-chemokines induced by HIV-2 envelope glycoprotein. AIDS 1997; 11: 1062-1063. 
26. Cavaleiro R, Sousa AE, Loureiro A, Victorino RM. Marked immunosuppressive effects of the HIV-2 envelope protein in spite of the lower HIV-2 pathogenicity. AIDS 2000; 14: 2679-2686.

27. Cavaleiro R, Brunn GJ, Albuquerque AS, Victorino RM, Platt JL, Sousa AE. Monocyte-mediated $\mathbf{T}$ cell suppression by HIV-2 envelope proteins. Eur $J$ Immunol 2007; 37: 3435-3444.

28. Rossio JL, Esser MT, Suryanarayana K, Schneider DK, Bess JW, Jr., Vasquez GM, et al. Inactivation of human immunodeficiency virus type 1 infectivity with preservation of conformational and functional integrity of virion surface proteins. J Virol 1998; 72: 7992-8001.

29. Frank I, Piatak M, Jr., Stoessel H, Romani N, Bonnyay D, Lifson JD, et al. Infectious and whole inactivated simian immunodeficiency viruses interact similarly with primate dendritic cells (DCs): differential intracellular fate of virions in mature and immature DCs. J Virol 2002; 76: 2936-2951.

30. Keir ME, Butte MJ, Freeman GJ, Sharpe AH. PD-1 and its ligands in tolerance and immunity. Annu Rev Immunol 2008; 26: 677-704.

31. Trabattoni D, Saresella M, Biasin M, Boasso A, Piacentini L, Ferrante P, et al. B7H1 is up-regulated in HIV infection and is a novel surrogate marker of disease progression. Blood 2003; 101: 2514-2520.

32. Meier A, Bagchi A, Sidhu HK, Alter G, Suscovich TJ, Kavanagh DG, et al. Upregulation of PD-L1 on monocytes and dendritic cells by HIV-1 derived TLR ligands. AIDS 2008; 22: 655-658. 
33. Lore K, Smed-Sorensen A, Vasudevan J, Mascola JR, Koup RA. Myeloid and plasmacytoid dendritic cells transfer HIV-1 preferentially to antigen-specific CD4+ T cells. $J$ Exp Med 2005; 201: 2023-2033.

34. Donaghy H, Gazzard B, Gotch F, Patterson S. Dysfunction and infection of freshly isolated blood myeloid and plasmacytoid dendritic cells in patients infected with HIV-1. Blood 2003; 101: 4505-4511.

35. Hsieh SM, Pan SC, Hung CC, Chen MY, Chang SC. Differential impact of latestage HIV-1 infection on in vitro and in vivo maturation of myeloid dendritic cells. J Acquir Immune Defic Syndr 2003; 33: 413-419.

36. Pacanowski J, Kahi S, Baillet M, Lebon P, Deveau C, Goujard C, et al. Reduced blood CD123+ (lymphoid) and CD11c+ (myeloid) dendritic cell numbers in primary HIV-1 infection. Blood 2001; 98: 3016-3021.

37. Duvall MG, Lore K, Blaak H, Ambrozak DA, Adams WC, Santos K, et al. Dendritic cells are less susceptible to human immunodeficiency virus type 2 (HIV-2) infection than to HIV-1 infection. J Virol 2007; 81: 13486-13498.

38. Foxall RB, Soares RS, Albuquerque AS, Cortesao CS, Victorino RM, Sousa AE. Increased frequency of CD25dimCD4+ T-cells in HIV-2 infection, a naturally occurring attenuated form of HIV-1. Clin Immunol 2008; 127: 158-167.

39. Gautier D, Beq S, Cortesao CS, Sousa AE, Cheynier R. Efficient thymopoiesis contributes to the maintenance of peripheral CD4 $T$ cells during chronic human immunodeficiency virus type 2 infection. J Virol 2007; 81: 12685-12688. 


\section{Figure Legends}

FIG. 1. Effects of HIV-2 Env recombinant protein (gp105 ROD) and chemically inactivated $H I V-2(H I V-2 T x)$ on DC differentiation. iDC were generated from monocytes cultured in medium containing GM-CSF/IL-4 in the absence or presence of gp105 ROD or HIV-2Tx. After 6 days, cells were cultured with or without LPS for 2 additional days. Expression of co-stimulatory molecules assessed by flow cytometry cultured in the presence of gp105 (A) or of $H I V-2 T x(\mathrm{C})$ : numbers in histograms represent the geomean fluorescence intensity of the surface molecules expressed on DC of one representative donor (out of 3). DC allostimulatory ability of DC generated in the presence of gp 105 ROD (B) or of HIV-2Tx (D): DC generated in the absence or presence of gp $105_{\mathrm{ROD}}$ or HIV-2Tx and matured with LPS were co-cultured with purified allogeneic T cells for 5 days; lymphocyte proliferation was

measured by $\left[{ }^{3} \mathrm{H}\right]$ thymidine incorporation and stimulation indexes were calculated by dividing the counts per minute (cpm) obtained in the DC: T cell co-cultures by the cpm obtained in the cultures of $\mathrm{T}$ cells alone; results are expressed as mean Stimulation Index \pm SEM of 3 donors. (E) Levels of p24 gag protein assessed by ELISA in supernatants collected after 7 day culture of phytohemagglutinin-stimulated PBMC infected with HIV2Tx or non-inactivated HIV-2 (HIV-2Mock), illustrating the absence of viral replication after AT-2 treatment.

FIG. 2. Impact of gp105 ROD and HIV-2Tx on DC maturationas well as on DC ability to secrete $T N F-\alpha$ and $I L-10$. iDC were generated from monocytes cultured in medium containing GM-CSF/IL-4 in the absence of HIV-2 Env. After 6 days, iDC were treated with gp105 ${ }_{\text {ROD }}$, HIV-2Tx or with LPS for additional 2 days. In parallel, cells were induced to 
mature with LPS in the presence of gp $105_{\mathrm{ROD}}$ or HIV-2Tx. DC phenotype was assessed by flow cytometry as illustrated in A (culture with gp105 ${ }_{\mathrm{ROD}}$ ) and C (culture with HIV-2Tx). Numbers showed in histograms represent the geomean fluorescence intensity of the surface molecules expressed on DC of one representative donor (out of 3). The DC allostimulatory ability was evaluated after co-culture of DC exposed to gp105 $5_{\mathrm{ROD}}$ (B) or to HIV-2Tx (D) with purified allogeneic $\mathrm{T}$ cells for 5 days. Lymphocyte proliferation was measured by $\left[{ }^{3} \mathrm{H}\right]$ thymidine incorporation and results are expressed as mean Stimulation Index $\pm \mathrm{SEM}$ of 3 donors, calculated by dividing the cpm obtained in the DC: T cell co-cultures by the cpm obtained in the cultures of $\mathrm{T}$ cells alone. (E) After 48 hours of culture of iDC with gp105 $\mathrm{ROD}, \mathrm{HIV}-2 \mathrm{Tx}$ with or without LPS, supernatants were collected and IL-10 and TNF$\alpha$ were measured by ELISA. The graphs show a representative case of the 3 different individuals tested for the effects of gp105 ROD (top) and a representative case of the 3 different individuals tested for the effects of HIV-2Tx (bottom). 


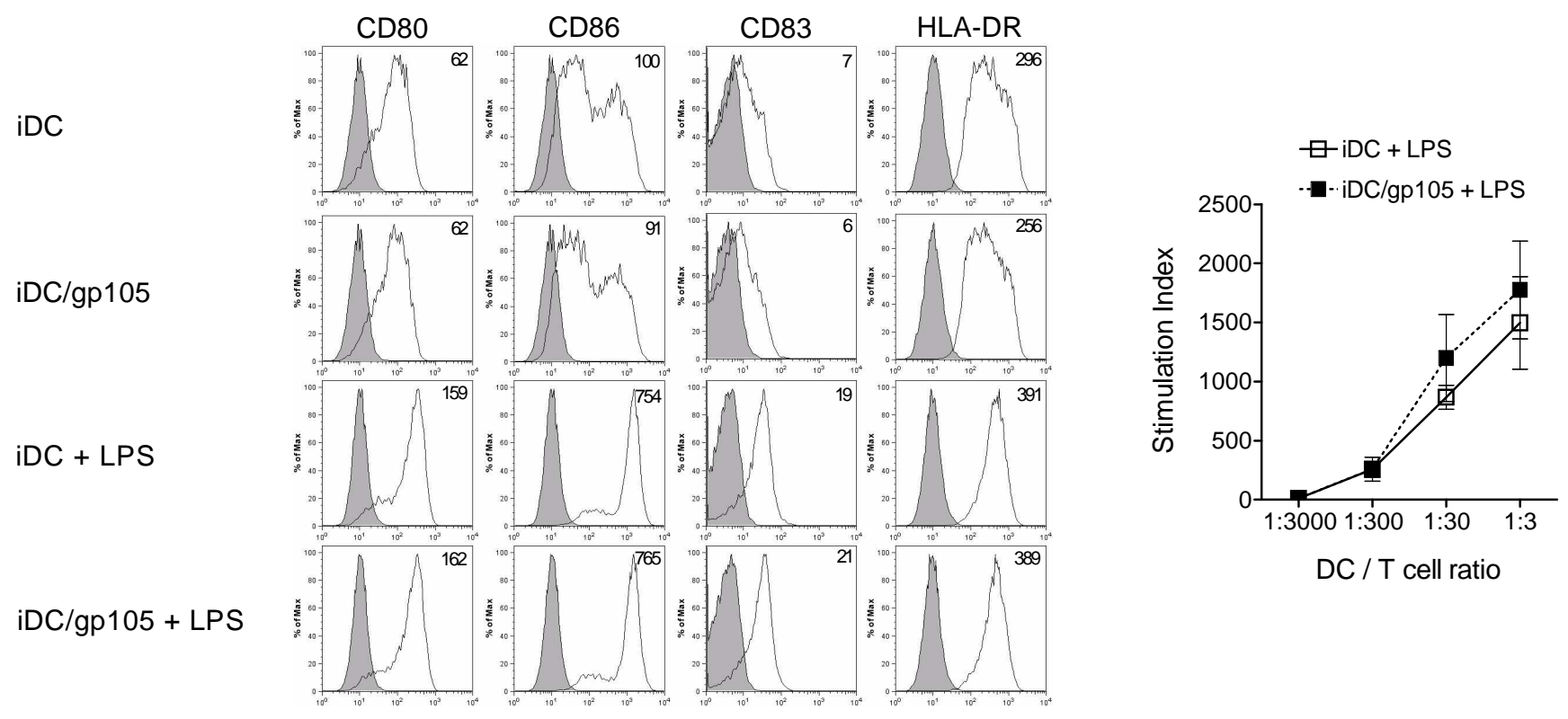

\section{C}

iDC

iDC/HIV-2Tx

$i D C+$ LPS
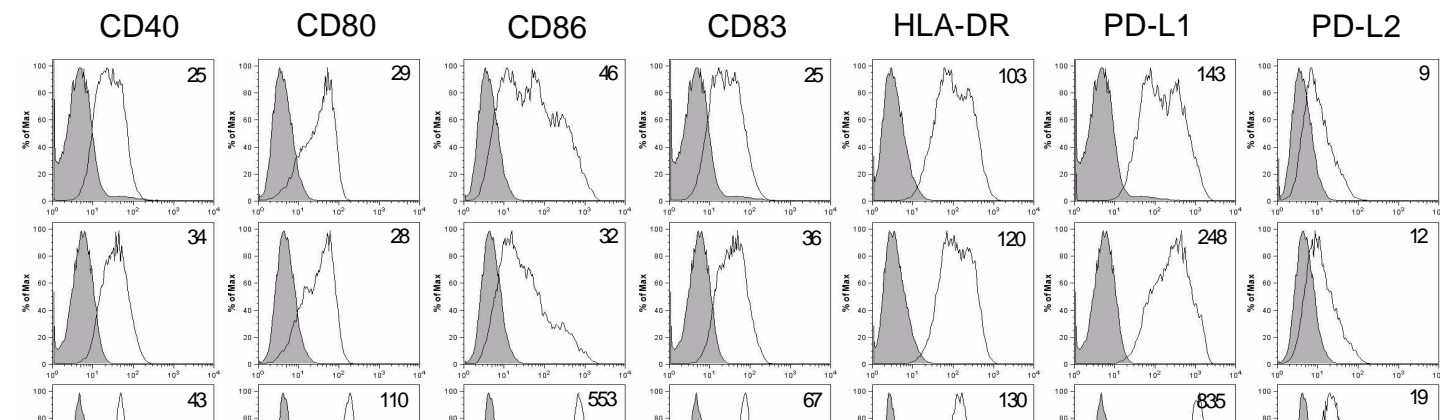

DC/HIV-2TX + LPS
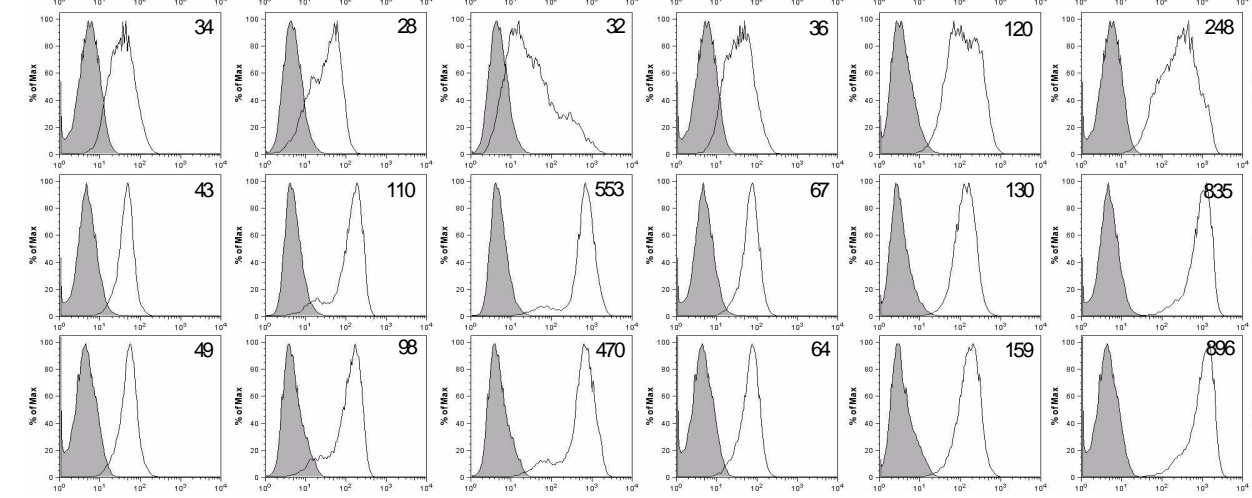

D

E
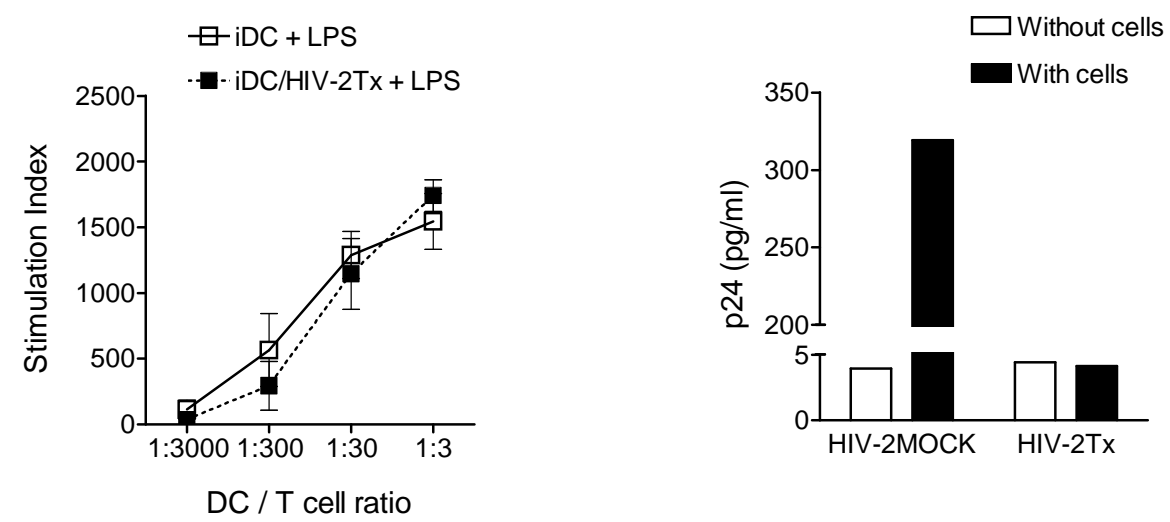
A
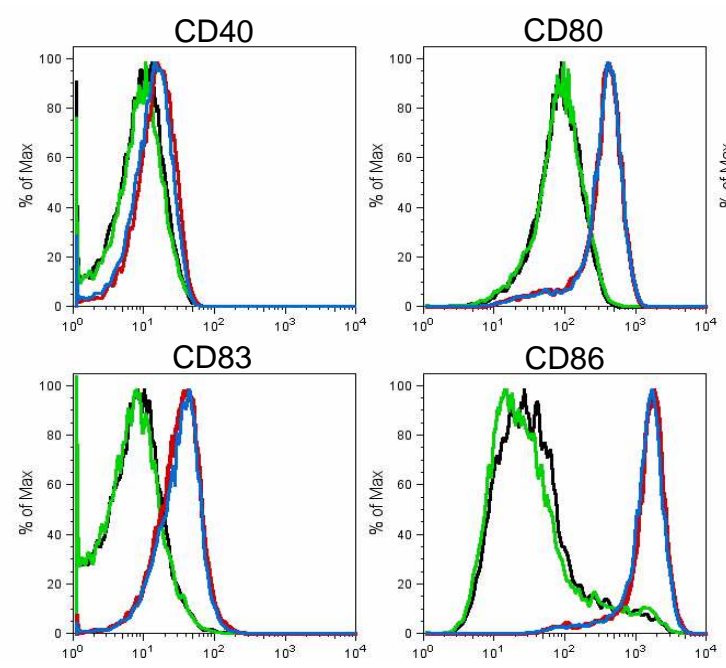

C
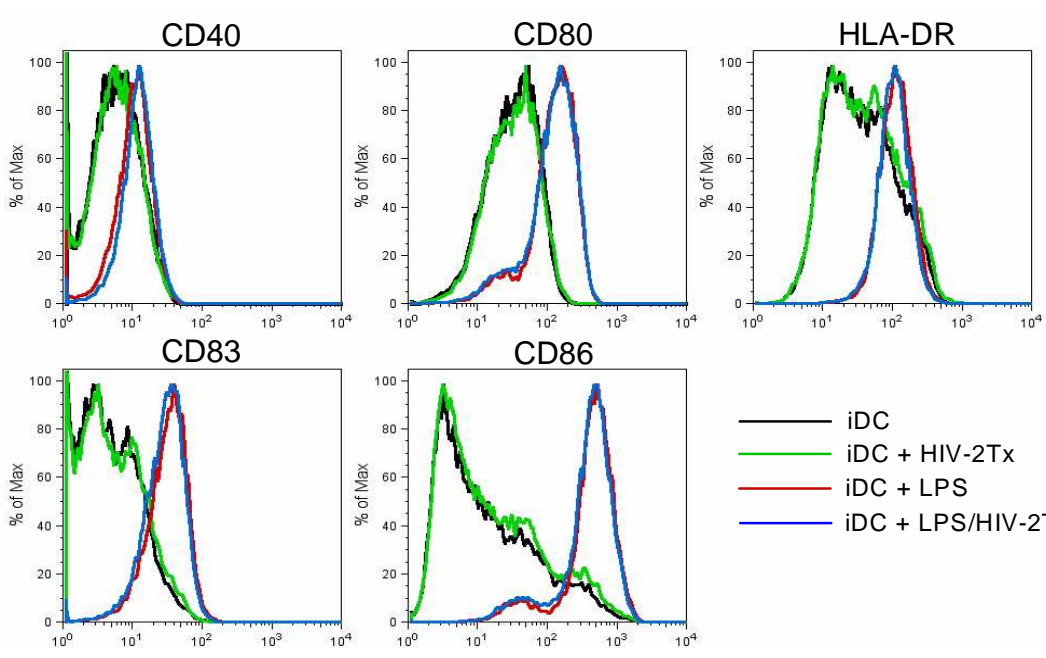

E
B
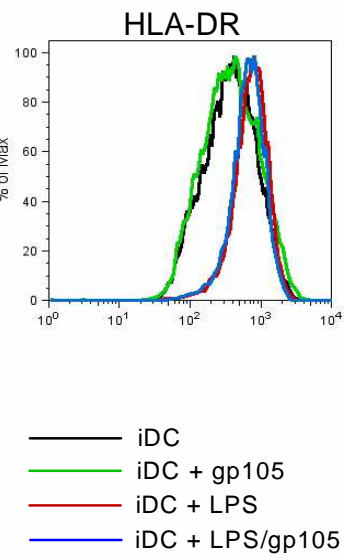

D
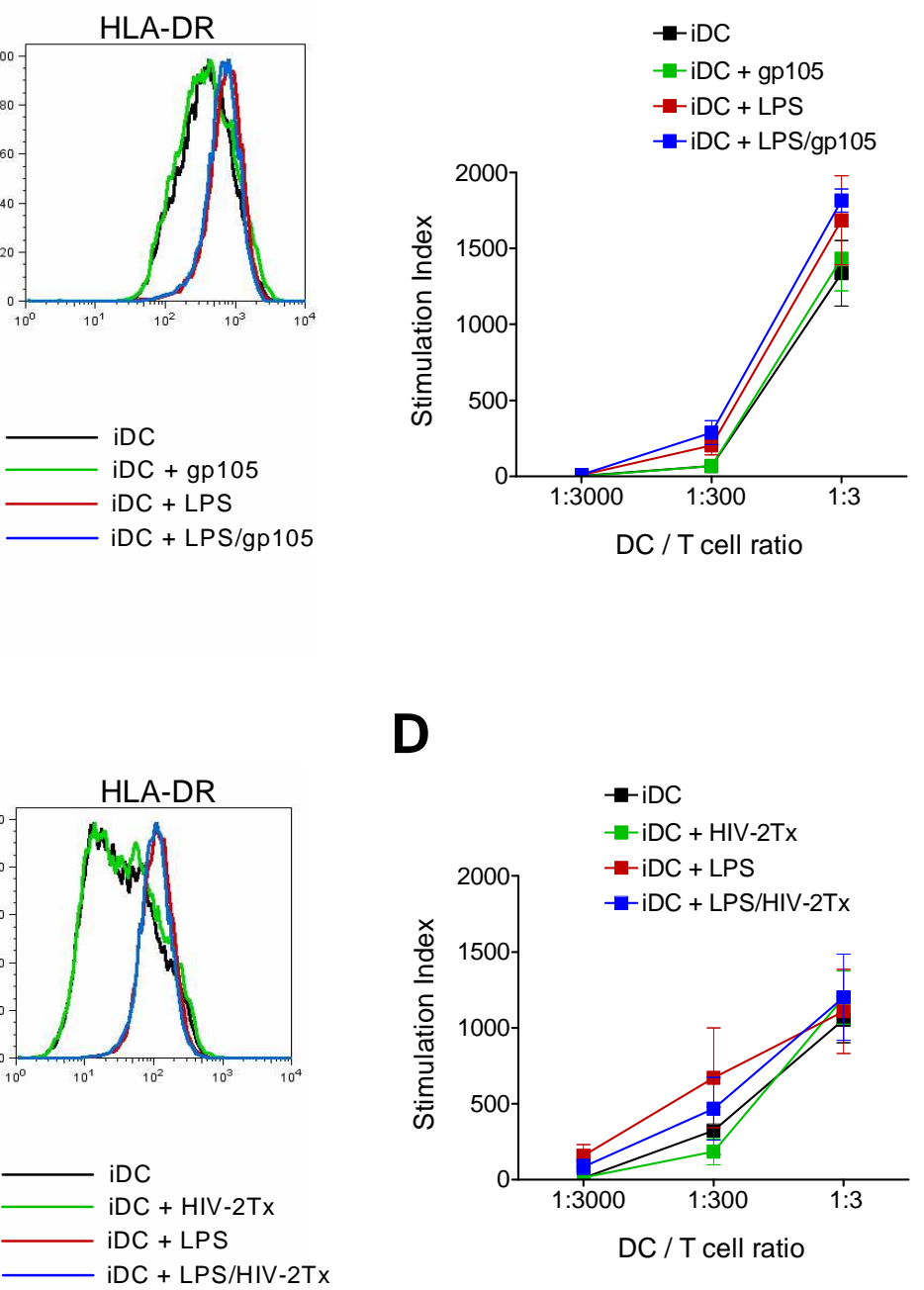

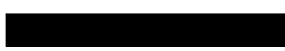

iDC + LPS/gp105

$i D C+$ LPS

$\mathrm{iDC}+\mathrm{gp} 105$

iDC

$D C+L P S / H I V-2 T X$

iDC + LPS

iDC + HIV-2TX

iDC

$400 \quad 300 \quad 200 \quad 100$
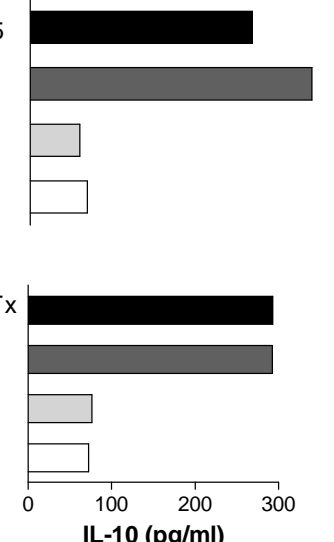

IL-10 (pg/ml) 
iDC
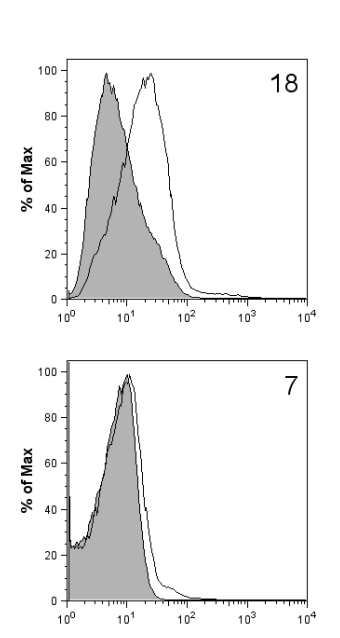
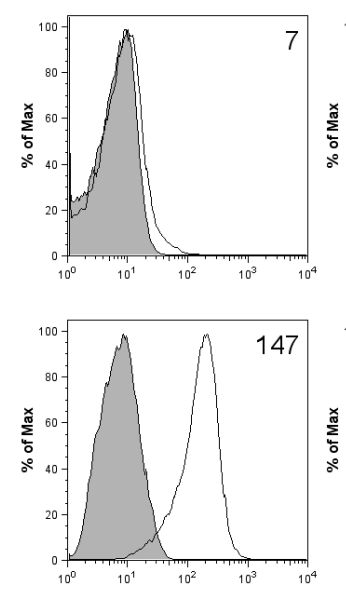

$\mathrm{iDC}+\mathrm{gp} 105$
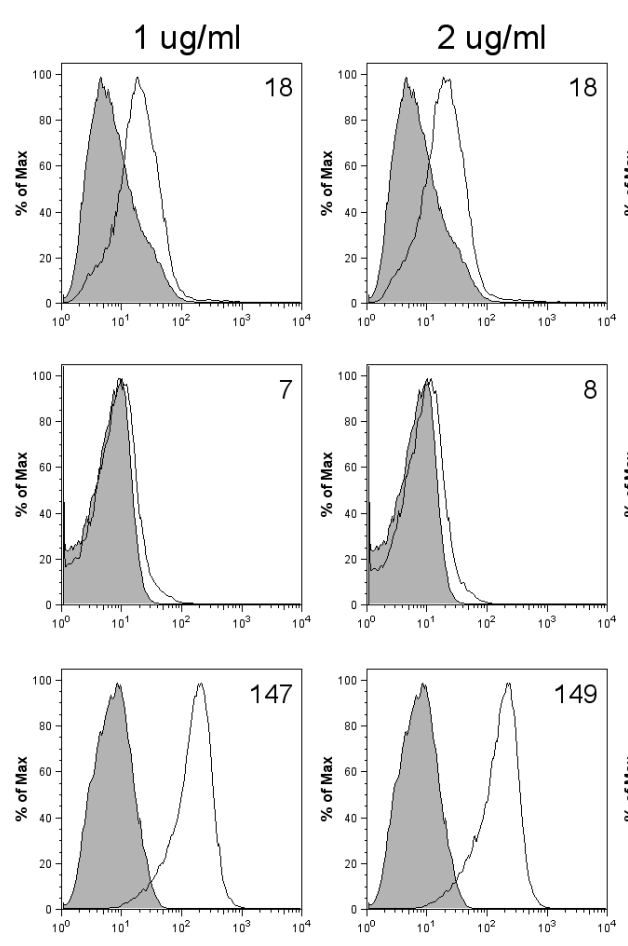

iDC + HIV-2Tx
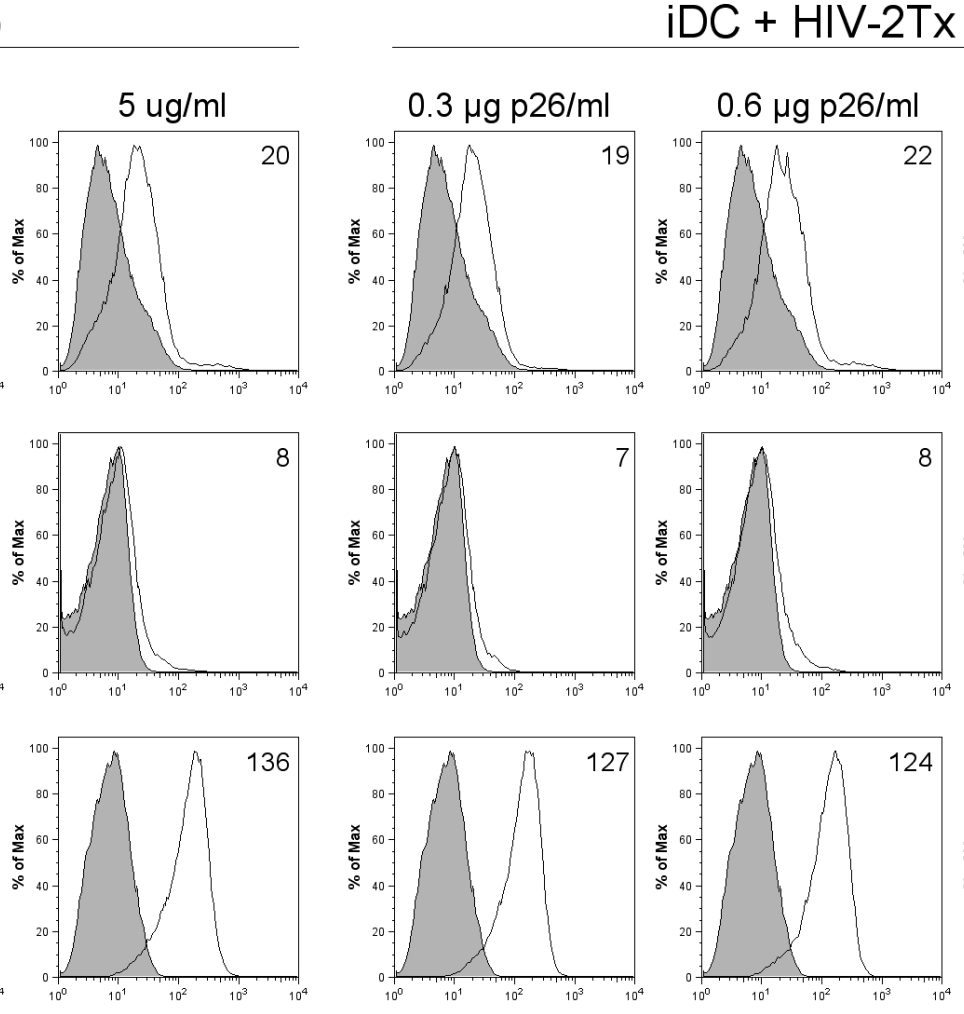

$\mathrm{iDC}+\mathrm{LPS}$
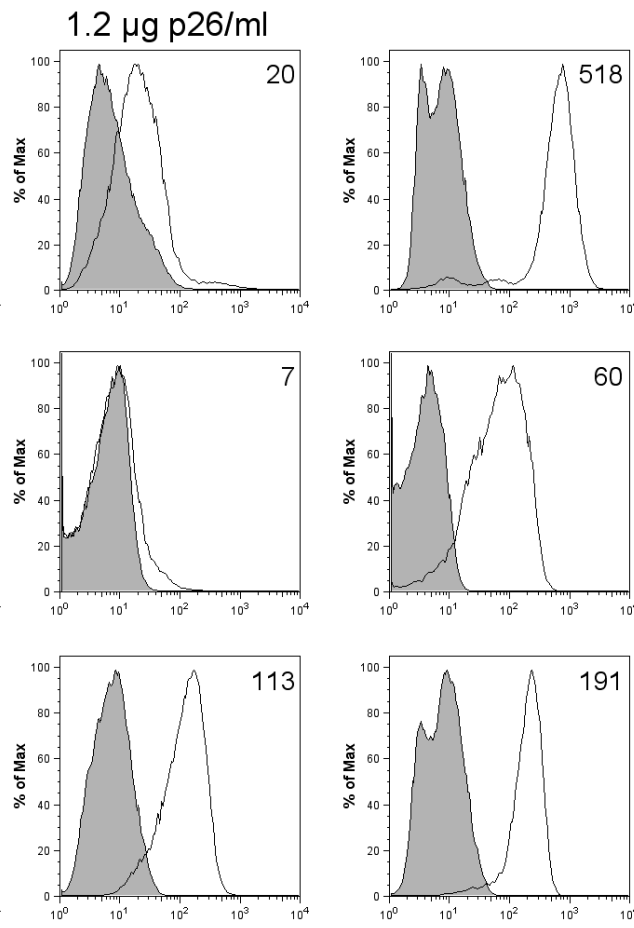

Supplemental Figure. Dose-dependent effects of gpl05ROD or HIV-2Tx on DC maturation.

iDC were generated from monocytes cultured in medium containing GM-CSF/IL-4. After 6 days, iDC were treated with increasing concentrations of gp105ROD $(1,2$ and $5 \mu \mathrm{g} / \mathrm{ml})$ or HIV-2Tx $(0.3,0.6$, and $1.2 \mu \mathrm{g}$ p26/ml $)$ or with LPS $(0.1 \mu \mathrm{g} / \mathrm{ml})$ for additional 2 days. DC phenotype was assessed by flow cytometry as illustrated. Numbers showed in histograms represent the geomean fluorescence intensity of the surface molecules expressed on DC. 